\title{
Exploring Knowledge Transfer at UC Engineering School
}

\author{
Hector Gaete Fica ${ }^{1}$
}

\begin{abstract}
I explore the degree to which patents represent magnitude of knowledge transferred from University to Industry. Building on the Agrawal \& Henderson (2002) framework, I compare two MIT engineering departments and the School of Engineering of the Pontificia Universidad Católica de Chile (UC Engineering). Based on quantitative and qualitative data I estimated the relative importance of patenting as a knowledge transfer mechanism. I found that in UC Engineering patenting and publishing activity have increased steadily, in line with faculty size increase. However, patenting is perceived by academics as a relatively less important technology transfer channel, and in terms of production counting it appears much less relevant. Although in terms of relative importance of publishing over patenting as a technology transfer channel both are relatively similar, in the perception of faculty; in terms of production counting there is a substantial difference. I suggest some plausible explanations, proposing new avenues for research.
\end{abstract}

Keywords: knowledge transfer; academic patenting; scientific publication.

Submitted: Jun $15^{\text {th }}, 2018 /$ Approved: September $10^{\text {th }}, 2018$

\section{Introduction}

In the absence of better innovation data, patents have frequently been used as indicators of industrial innovation (Kleinknecht \& Jan Reinders, 2013). Patenting, however, is only one of more than 20 different knowledge transfer mechanisms between universities and industries (Bekkers \& Bodas Freitas, 2008). Estimating the nature and magnitude of the different knowledge transfer channels and its impact on industry remains difficult, although this is important for academics, universities and governments. University professors might be evaluated or provided incentives for knowledge transfer; yet defining a metric for calculating these incentives is difficult and might be counterproductive if important knowledge transfer channels are neglected. Universities are pursuing a 'third mission' by fostering links with knowledge users and facilitating technology transfer to society, thus knowing which channels are utilized can provide information on how to manage the collaborations with external partners. Governments, in trying to stimulate economic growth and solutions to public problems, encourage universities to transfer knowledge and to develop institutions that enable the "third mission"; yet in the absence of indicators it's hard to allocate resources. Thus, this matter is of great relevance for policy-makers who attempt to stimulate the diffusion of university-generated technologies within the wider economy.

In this paper, I explore the degree to which patents are representative of the magnitude and impact of the knowledge transferred from University to Industry. I build on the framework developed by Agrawal \& Henderson (2002) who used quantitative and qualitative data to estimate the relative importance of patenting as a mechanism for knowledge transfer from two selected engineering departments at MIT. Johnson sustains that some important groundbreaking technologies have stemmed from university-based work, but evidence suggests that many of these have been the products of only a few en- trepreneurial universities with engineering schools such as at MIT and Stanford (Johnson, 2011). The US ranked second in intellectual property filing activity by origin in 2016 (World Intellectual Property Organization, 2017). Within the US, the MIT was the second university to which more patents (278) were granted in 2016 (National Academy of Inventors, 2017). I replicated to some extent the already mentioned study, focusing on a particular setting: the School of Engineering (hereafter UC Engineering) of the Pontificia Universidad Católica de Chile (hereafter UC), one of the Chilean leading higher education organizations. Drawing on a survey questionnaire applied to the faculty of the UC Engineering ten departments; together with quantitative information about each faculty member's patenting and publication record, I consider to what extent patents are perceived in terms of magnitude and impact, compared to other channels, of the knowledge transferred from UC Engineering to industry. Data available was scarce and contemporary, due to the recent organization and strengthening of intermediation structures in the UC and UC Engineering.

I found that patenting is an activity undertaken by a small portion of the faculty members at UC Engineering. In addition, although in terms of relative importance of publishing over patenting, as a technology transfer channel, they are relatively similar in the perception of UC Engineering and MIT faculty, in terms of production counting strong differences are shown. This is the biggest difference that I found. In respect to the exploration about the degree to which patents are representative of the magnitude of the knowledge transferred from university to industry, I found that in UC Engineering, in general, during the last 10 years patenting and publishing activity have been increasing steadily in line with faculty size increase. However, patenting is perceived by academics as a relatively less important technology transfer channel, and in terms of production counting, it appears much more less relevant. 
I speculate that, with the aim to achieve a more straightforward transfer of academic knowledge into the industrial domain, enabling elements are funding availability, organizational attention to academics productivity in terms of academic entrepreneurial culture and career promotion rules, and alignment to strategic objectives. In particular, the latter on the objective of helping domestic economy to find its future and sustainable competitive advantage.

This paper contribution lies in a deeper understanding of the degree to which patents are representative of the magnitude of the knowledge transferred from university to industry. First, uncovering particulars of patenting and publishing at UC Engineering. Second, analyzing and comparing them to previous research looking at the MIT. Third, paying attention to the extent to which patents are complementary or substitute for publications in the university context. Finally, speculating about the enablers for a more thorough knowledge transfer. To sum up, effective and sustainable knowledge and technology transfer from university to industry requires evidence about the nature and magnitude of different technology transfer channels. This work contributes to a richer understanding of the complex nature of technology transfer activity in a university setting. In particular, this research look at faculty in a developing country, in a specific engineering school, allowing to look at a 'local' social environment, thus minimizing the heterogeneity of a broader context.

The exploratory nature of this study builds on the broad, but still fragmented and at times contradictory, literature on technology transfer from university to industry. Also, on the very few studies that consider engineering academics or the context of a developing country, and few pieces of research that look at engineering settings. The paper is organized as follows; section 1 introduces the aim of exploring knowledge transfer in the specific setting. Then, section 2 considers gradually the notion of knowledge transfer channels, patenting and publishing. Subsequently, section 3 presents the data and the methodology used. Finally, section 4 discusses the results and concludes the paper.

\section{The nature of knowledge and technology transfer channels, patenting and publishing}

Valuable technological capabilities are built incrementally over time. Petralia et al found that having capabilities in related technologies is important for a country when entering into a new technological domain, the likelihood a new technological capability will emerge is higher the closer that technology is with respect to the profile of existing capabilities of the country (Petralia et al, 2017). This effect diminishes as countries develop as results show that diversification in unrelated technologies is less likely to occur at early stages of development (Petralia et al, 2017). They found a significant and positive reinforcement of having developed related capabilities, implying that technological production tends to cluster in the technological space. Furthermore, according to their findings, the likelihood of specialization increases for complex and valuable technologies as countries develop (Petralia et al, 2017). In short, countries climb the ladder of technological development gradually, changing patterns as countries develop. In any case, in the global value chain, countries that innovate are able to capture a larger share of the value added, while others are trapped in less profitable activities (Petralia et al, 2017).

Technology transfer can be considered a complex and systemic phenomenon. Knowledge transfer is not a single homogenous concept, it can occur through a number of routes, both formal and informal, referred to as "research commercialization" such as patents, licenses and spin outs, or "academic engagement", with the most popular being contract research, collaborative research and consulting (Sengupta \& Ray, 2017). As a whole, Bozeman et al suggest that technology transfer activity is one significant event in a multi-casual chain of events (Bozeman et al, 2015). Further, Landry et al maintain that there are complex interactions among multiple forms of mutually reinforcing knowledge transfer activities that lead to enhanced performance in the knowledge transfer of individual academics, representing a knowledge transfer system made up of interdependent and mutually reinforcing activities (Landry et al, 2010). Moreover, Perkmann et al argue that this transfer is a multi-level phenomenon, in the sense that is determined by both the characteristics of individuals as well as the organizational and institutional context in which they work (Perkmann et al, 2013). Similarly, regarding portfolio management of knowledge transfer activities, decision makers have to manage complex social systems whose constituents and interactions are usually incompletely understood and whose benefits only become apparent post hoc (Landry et al, 2010). In practice, academics may make joint decisions for multiple knowledge transfer activities rather than treating them independently, due to the presence of complementarities that arise from interrelated knowledge transfer activities, allowing exploiting opportunities for cost saving, as well as drawing on tacit interrelated skills (Landry et al, 2010). Regarding the factors which determine the propensity of academic scientists to engage themselves in commercialization activities, Arvanitis et al suggest that there exists some kind of trade-off between financial motives because of the perspective of additional income, the inherent motives of a scientist who primarily pursues research goals and the reputation associated with research achievements (Arvanities et al, 2008). Johnson suggests that tying the outcomes of the innovation venture to the reward structure of the scientists involved in the university - industry technology transfer process may be an effective way of motivating innovative behavior (Johnson, 2011). Thus, technology transfer activity is seen as a complex, multi-level phenomenon, made up of interdependent activities.

Technology transfer channels must be carefully considered because they are not completely understood yet. Bekkers \& Bodas Freitas suggest that the perceived relative importance between technology transfer channels hardly differs between industry and university; still, differences in importance of various channels of knowledge transfer are not related to industrial sectors if not rather by basic characteristics of the knowledge in question, disciplinary origin of the knowledge involved, and, to a lesser extent, to individual and organizational characteristics of those involved in the knowledge transfer (Bekkers \& Bodas Freitas, 2008). Regarding more granular literature on technology transfer channels, they noted that a few studies have shown 
that differences exist in the forms of knowledge transfer across different disciplines and industrial activities; however, the patterns of knowledge transfer from university to industry still have to be explored systematically across sectors with different learning patterns and different level of technology opportunities, to find explanations underlying these patterns (Bekkers \& Bodas Freitas, 2008). Moreover, they found no consensus on the channels through which knowledge flows between university and industrial firms. Some authors argue that firms consider codified output, such as publications and patents, the most important form of accessible knowledge that is being developed by a university, whereas others contend that the most important channels for universities to have an impact on industrial $R \& D$ are published papers and reports (Bekkers \& Bodas Freitas, 2008). In any case, Van Looy et al found no evidence of any trade-off between the different technology transfer mechanisms (Van Looy et al, 2011). Bekkers \& Bodas Freitas summarize their findings about knowledge transfer channels related to industry sectors in existing literature through four ideas. First, publications, participation in conferences and collaborative research are particularly important in $\mathrm{R} \& \mathrm{D}$-intensive industrial activities. Second, influx of students, contract research and collaborative research are expected to be specially important in the engineering field. Third, patents, spin-offs and collaborative research are expected to be of major importance for firms active in science-intensive industries. Finally, informal contacts are not expected to differ significantly across sectors (Bekkers \& Bodas Freitas, 2008). To sum up, there is no consensus on technology transfer channels relative importance and patterns.

The growing relevance of technology transfer has brought new concerns. In a knowledge economy, science is exerting an increasingly large influence on innovation, especially in fast-growing knowledgeintensive industries (Arvanitis et al, 2008). The intensity and variety of activities at the University - Industry interface is growing and it is crucial to improve our understanding of which university researchers are interacting with firms (Giuliani et al, 2010). In addition, universities are becoming increasingly proactive managers of their collaborations with industry, seeking to create valuable intellectual property to foster technology transfer (Bruneel et al, 2010). In this respect, government agencies and universities themselves have made concerted efforts to increase the transfer of academic knowledge into the industrial domain, for reasons ranging from generating societal legitimacy for publicly subsidized scientific research, stimulating economic activity, to raising revenue for universities (Perkmann et al, 2013). Research demonstrating the potential of universities to contribute to regional economic growth and to be instrumental in the formation of new industries has led to a greater policy focus on the role of universities in engaging with businesses and undertaking knowledge transfer activities (Hewitt-Dundas, 2012). Overall, some authors argue that the 'third role' played by universities conflicts with research and higher education in the absence of adequate resources (to be devoted to this specific aim) and of indicators of this type of output, which are taken into account to assess the advancement of scholars' careers (Maietta, 2015). In particular, capabilities, in the broad context of university commercialization of research results, are built over time and cannot be implemented simply by setting up structures and policies
(Rasmussen \& Borch, 2010). Specifically, bottom up processes from within the university can be important in developing these capabilities (Rasmussen \& Borch, 2010). Consequently, to foster technology transfer, a clearer understanding of this activity in itself is necessary. An engineering setting can pose an attractive context for technology transfer. Arvanitis et al found that institutes of economics and business administration, natural sciences, engineering and medicine are stronger involved in knowledge and technology transfer activities than institutes of mathematics and physics (Arvanitis et al, 2008). Further, Perkmann et al suggest, on the institutional level, strong association between transfer and affiliation to engineering; as well as support for the notion of transfer of academic knowledge into the industrial domain as complementary to traditional academic science in research looking at engineering faculties (Perkmann et al, 2013). In this respect, Crespi et al found evidence of a subtle scientific field effect where computer sciences and engineering showed a crowdingin effect between patenting and publishing; however, they also found indications that beyond a certain threshold, a continuing focus on patenting can result in a negative effect on other channels of knowledge diffusion such as publishing (Crespi et al, 2011). Some authors argue that academic engineering faculties are specially positioned to undertake technology transfer, but research is needed to explain some inconsistencies drawn from evidence.

There are a number of avenues open for research on technology transfer. Overall, Perkmann et al suggest that research published on the transfer of academic knowledge into the industrial domain remains relatively fragmented and tentative (Perkmann et al, 2013). In addition, Bodas Freitas et al maintain that despite there is an extensive body of literature on University - Industry collaboration in developed and newly industrialized countries, no work has been published on whether and how the establishment, content and organization of University - Industry collaboration differ between emergent and mature industries (Bodas Freitas et al, 2013). In this respect, explaining why academics become involved in entrepreneurial ventures is a domain that has received increased levels of interest from academics and practitioners (Clarysse et al, 2011). A number of authors suggest that the sparse pertinent literature claim for further research on technology transfer, to understand how universities can foster University - Industry links, in order to facilitate this activity. This knowledge is highly relevant for universities and policy makers seeking to increase the impact on the industrial domain, and subsequently economy and people.

\section{Patenting and publishing}

Patenting and publishing are important to this research because of the potential complementary or competing relationship amongst them. Landry et al suggest that publications, patenting, spin-off creation, consulting and informal knowledge transfer are complementary activities (Landry et al, 2010). Moreover, generally speaking, complementarity effects among patenting, spin-off formation, consulting, informal knowledge transfer and publications emerge under four conditions: finance linked to private funding, the degree of novelty of research findings, network assets, and organizational assets linked to the size of 
research units and the research intensity of the universities (Landry et al, 2010). In this respect, Crespi et al maintain that academic patenting may be complementary to publishing at least up to a certain point, after which there would be a substitution effect (Crespi et al, 2011).

Patents are widely used in the innovation literature because they provide a systematic and quantitative measure of new technological inventions, but they are also criticized because they only capture some specific types of innovation and technologies (Petralia et al, 2017). Many generic forms of innovation, especially in developing countries, won't show up in patent data (Petralia et al, 2017). Conversely, the use of secrecy over patenting as a method of protection cannot be measured unless a firm-level survey spanning different technological domains is conducted (Petralia et al, 2017). In any case, a long period is necessary to ascertain the effects of collaboration between national systems of innovation's actors and industry, after accounting for cross-sectional and time heterogeneity (Maietta, 2015). In coherence with this view, looking for accuracy in metrics based on activity, Bozeman et al suggest that measures need to be tracked over time. They point out that the US Department of Energy, rather than simply reporting the number of patents, report the ratio of patents in a given year to patent applications filed for a three year base period, using a rolling three-year average (Bozeman et al, 2015). Nevertheless, they emphasize that for any valid inference about effectiveness, activity measures must relate to resource measures (Bozeman et al, 2015).

Crespi et al argued that findings are mixed with regards to the relationship between patenting and publishing among academics. While there is some statistical evidence of a complementary effect (co-occurrence) between publishing and patenting, there is also qualitative and quantitative evidence of crowding out, highlighting the presence of non-linear relationships between patenting and publishing (Crespi et al, 2011). It is also suggested that patents and publications can result from one and the same underlying research effort, showing a positive relation at the individual professor and scientist level (Van Looy et al, 2011). Both activities share the objective of advancing knowledge and the state-of-the-art, in science and technology, respectively (Van Looy et al, 2011). In any case, Van Looy et al found that the level of scientific productivity is the only variable consistently (and positively) related to levels of entrepreneurial activity (Van Looy et al, 2011). In consistency with this view, Perkmann et al suggest that academics who generate high numbers of publications in peerreviewed journals also excel at patenting and academic entrepreneurship, although compared to alternative channels of interaction patenting and academic entrepreneurship are only moderately important (Perkmann et al, 2011). To sum up, patenting is commonly used as a measure of innovation or technology transfer. Although as Bruneel et al maintain, it is unclear whether the changes that have occurred in university patenting activity are a direct consequence of technological changes or of policy (Bruneel et al, 2010).

As a final point, it is important to underline the increase of Chilean policies and incentives aimed at stimulating $R \& D$ and technological transfer from academia to the industrial domain. This, since the introduction of an industrial property law (1991) and the tax incenti- ve for R\&D investment law, enacted in 2008, has generated growing interest in the magnitude and impact of patenting in terms of the knowledge transferred from university to industry.

\section{Data and methods}

UC Engineering was selected in this work because the author works in DICTUC SA, a company affiliate to the UC, dedicated to transfer knowledge and technology generated by UC Engineering, so as to place it at the service of the community, through individual or multidisciplinary services (Pontificia Universidad Católica de Chile, 2016). DICTUC links academia and research to productive sectors of the country, providing multidisciplinary engineering services to solve specific problems and developing large, relevant and diverse projects, in order to positively impact people, by giving concrete solutions to the challenges of society (DICTUC, 2016). Another reason is because the university is one of the premier higher education organizations in Chile. The university obtained the first place of Latin American universities in the QS 2018 ranking, after being third in the 2017 ranking. Furthermore, MIT ranked UC Engineering in the fourth position of its 2017 global ranking of emerging engineering institutions with a better projection for the coming years. UC Engineering was behind the University of Technology and Design of Singapore, which ranked first, Olin College of the US (second) and University College London (third). This is important in respect of technology transfer as those universities with highest research quality will be most likely to engage in knowledge transfer (Hewitt-Dundas, 2012). Besides, the university was the Chilean organization that filed most patent applications for invention in Chile in 2015. Within the UC, the areas with the highest number of patent applications are life sciences, with more than a third, followed by engineering and construction, and the rest are divided into design, food, chemical processes, and others. Finally, UC Engineering's leadership highlights the critical role that applied disciplinary and interdisciplinary research will play in helping economy find its future and sustainable competitive advantage to tackle the increasingly complex shared concerns of Chilean people and society (Pontificia Universidad Católica de Chile, 2016). In summary, UC engineering is committed to become a worldclass school of engineering, recognizing that a critical path in this realm has to do with orchestrating capabilities that finally use knowledge and technology as a vehicle to impact society as well as global markets. As a result, this specific setting seems well suited to explore the nature of knowledge and technology transfer at UC Engineering with focus on publishing and patenting behavior of faculty members.

The data for this work is based on the population of professors who were on the faculty on December 2017 and who generated at least one paper or patent during the period January 2008 -- December 2017. This added up a total of 111 professors. I chose to focus on this period because publication and patenting data were available for those years. Our final data set includes information about 47 patents and 2,090 papers, allocated to the sample faculty. Paper data was collected from Dimensions of National Scientific Production, the Scientific Information Program CONICYT (DataCiencia), (CONICYT, 2017) for some selected universities chosen, and the records of the UC Engineering's Directorate of Innovation and Research for UC Engineering. Patent data 
was collected from the Chilean National Institute of Industrial Property (INAPI) for the selected universities, and the records of the UC's Direction of Transfer and Development for UC Engineering. The year of the patent is the application year, which is the more closely approximating the invention date. Publications have been dated in the year of publication because that is the only date available in a reliable manner.

This work resorts to both qualitative and quantitative data. Due to the exploratory nature of this effort, I focus on a single university and in particular, one engineering faculty made of 10 departments. The core of this work is the consideration of the professors currently working on a full time basis at UC Engineering. I have to highlight the originality of this research, in the setting of one engineering school in a developing country. In this particular context, literature regarding technology transfer from university to industry in general, and from an engineering school in particular, is almost inexistent.

I supplemented quantitative data with a survey questionnaire aimed to collect quantitative as well as qualitative data. I requested every faculty member to answer a survey questionnaire during the twoday's UC Engineering strategic planning workshop held on January 2018. To develop the questionnaire, I conducted a few interviews with academics and reviewed the literature. The survey asked about academics' demographics as well as perceptions on their research and on channels of knowledge transfer. Of the faculty members, $66 \%$ agreed to answer, resulting in a sample size of 73 .

\section{Results}

\section{Sample characteristics}

Table 1 presents basic descriptive statistics for professors that were faculty members in December 2017 who generated at least one paper or patent application, contrasted with the faculty members who had filled at least one patent application between 2008 and 2017 (Academic inventors). The academic inventors published about 50\% more than the population mean and patented a great deal more (over 5 times) and were active over $50 \%$ more time during the period considered (longer tenure).

Table 1 Descriptive statistics for the total population and Academic inventors

\begin{tabular}{|c|c|c|}
\hline & Total population & Academic inventors \\
\hline $\mathbf{N}$ & 111 & 22 \\
\hline \multicolumn{3}{|l|}{ Publications } \\
\hline Standard deviation & 15.2 & 18.4 \\
\hline Median & 15 & 24.5 \\
\hline \multicolumn{3}{|l|}{ Patents } \\
\hline Mean & 0.4 & 2.1 \\
\hline Standard deviation & 1.1 & 1.4 \\
\hline Median & 0 & 1 \\
\hline Mean & 13.4 & 20.6 \\
\hline Standard deviation & 10.5 & 9.5 \\
\hline Median & 11 & 21 \\
\hline Maximum & 43 & 43 \\
\hline Minimum & 1 & 4 \\
\hline
\end{tabular}

Source: Records, Directorate of Transfer and Development Pontificia Universidad Católica de Chile, December 2017 (Patents); and Records, Directorate < of Innovation and Research, School of Engineering, Pontificia Universidad Católica de Chile, December 2017 (Publications).

\section{Patenting and publishing, two channels for technology transfer}

A increase in scientific publication and patenting has been recorded during the last few years in Chile. Figure 1 shows total patents assigned to six selected universities in Chile between 2008 and 2015. Between 2008 and 2014, despite fluctuations from year to year, the universities increased significantly the number of patents granted, between $50 \%$ and $238 \%$, with the exception of the Austral University, with a decrease of 33\%. For example, while the UC was granted eight patents in 2008, in 2014 the figure reached 21, a 163\% of increase. Further explanation requires the sudden decrease in activity in 2015 , for all of the universities in the sample, possibly due to incentives in 2014 that boosted a specific year, restrictions of public resources for R\&D in the immediately preceding years, or an economic slowdown during these years. A supplementary explanation could be recent incentives to universities for technology transfer facilitation, which resulted in the patenting peak observed in 2014. 
Figure 1 Selected universities patenting over time

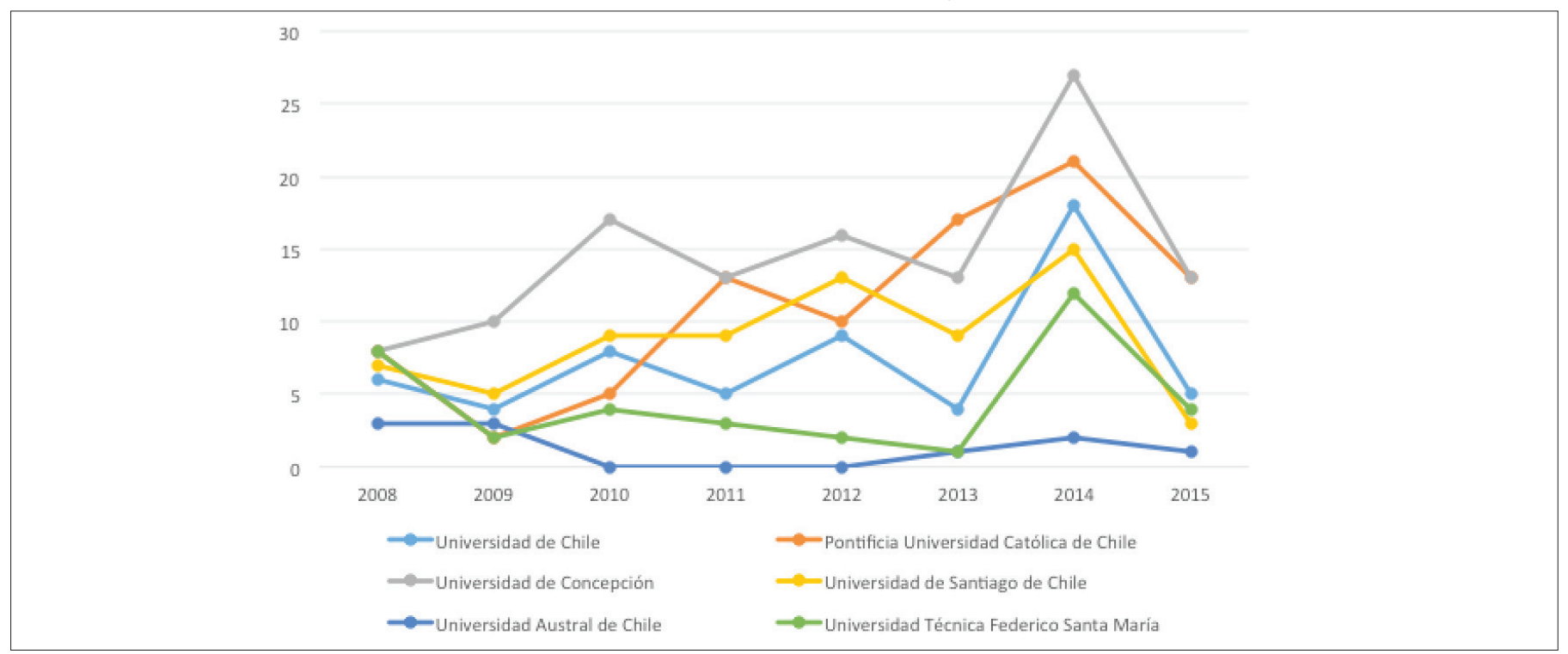

Source: National Institute of Industrial Property (INAPI) records for patent applications, November 2017.

Figure 2 shows patenting and publishing data over time for the academics of UC Engineering that patented or published at least once between 2008 and 2017. On the one hand, a clear upward trend can be seen regarding publications, which increased by $189 \%$ in the period. On the other, patents showed an upward trend, with a decrease in 2012, and a sudden fall in 2016 with a swift recovery in 2017. The difference in patenting in 2015 between Figure 1 and Figure 2 (i.e. between selected universities and UC Engineering), where the selected universities had a sudden decrease in 2015, whereas UC Engineering experienced a fall in the following years could be, allegedly, attributed to recent work to speed up patenting applications at UC Engineering that was completed in 2015. Figure 2 also shows that publication counting is much more higher than patenting. It is much more important, at least measuring counting data. While the average faculty member publishes a ratio between 2.3 and 3.7 papers per year, they produced between 0.03 and 0.09 of a patent. Notwithstanding, it is relevant to note that the number of academics increased steadily from 56 to 111 during the period. To sum up, for UC Engineering in the period considered, publishing rates increased in a threefold manner, the number of academics doubled, and patenting fluctuated with a slightly upward trend that fell in 2016 but recovered in 2017.

There is a potential limitation in respect of possible survivorship bias, a common type of sample selection bias; because our population consists of professors that were in the faculty in December 2017, thus faculty that left over the period has been systematically excluded. It is possible that our results would be distorted if "weak" faculty left.

Figure 2 Papers and patents at UC Engineering

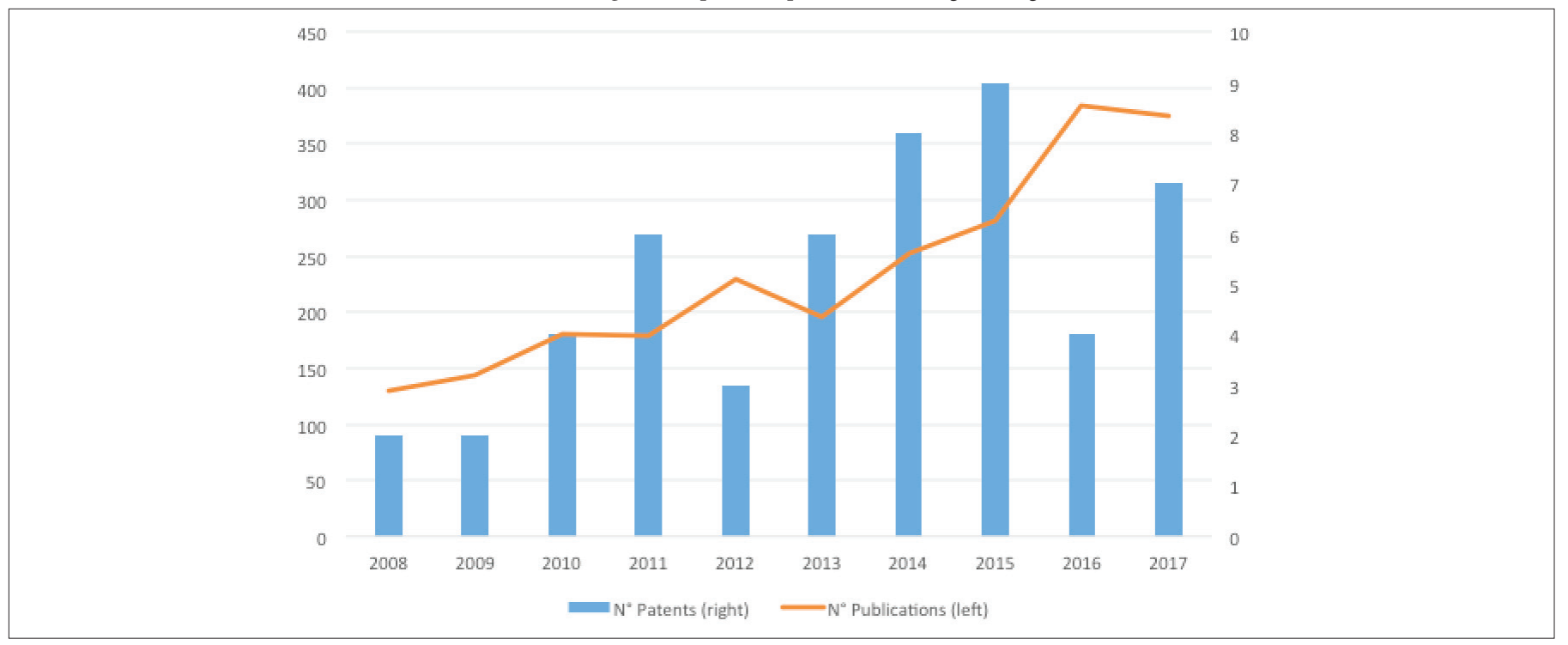

Source: Records, Directorate of Transfer and Development, Pontificia Universidad Católica de Chile, December 2017 (Patents); and Records, Directorate of Innovation and Research, School of Engineering, Pontificia Universidad Católica de Chile, December 2017 (Publications). 
Note that the ratios for data presented in Figure 2 considered the number of full time academics that have published or patented at least once in the period considered. The ratios considered the number of academic tenured each year because faculty increased progressively every year, from 56 in 2008 up to 111 in 2017. It has not been taken into account academics that entered and left faculty between these years.

Table 2: Average publications and patent rates per academic per year

\begin{tabular}{l|c|c|c}
\hline & Publications & Patents & Period \\
\hline UC Engineering & 2.9 & 0.06 & $2008-2017$ \\
\hline $\begin{array}{l}\text { MIT, two Engineering } \\
\text { Depts. }\end{array}$ & 1.8 & 0.25 & $1983-1997$ \\
\hline
\end{tabular}

Source: Agrawal \& Henderson. Putting Patents in Context: Exploring Knowledge Transfer from MIT. Management Science Vol. $48 \mathrm{~N}^{\circ} 1$, January 2002 (MIT Publication and Patents). Records, Directorate of Transfer and Development, Pontificia Universidad Católica de Chile, December 2017 (UC Engineering Patents); and Records, Directorate of Innovation and Research, School of Engineering, Pontificia Universidad Católica de Chile, December 2017 (UC Engineering Publications).

When these averages for faculty members are compared to data gathered by Agrawal \& Henderson (2002) in his work focused on two MIT engineering departments (See Table 2), the ratios are 1.5 and 2.0 (average 1.8) for publishing and about 0.25 for patents. This situation suggest a much higher relative importance of publishing over patenting in UC Engineering when compared to the sample from the MIT. An alternative explanation could be that publications do not refer to technologies that could be patented.

It is essential to underline that this comparison is anecdotal. There is a gap in time of about 10 years between the two populations considered, and they are not comparable in a straightforward manner, as UC Engineering is a complete faculty, comprised by ten departments, covering a broad array of engineering disciplines, compared to the MIT's departments of Mechanical Engineering, and Electrical Engineering and Computer Science. In addition, the 2017 Chilean National Innovation Strategy for Development points out that the complete set of national science corresponds to that of a good medium-sized US research university (Consejo Nacional de Innovación para el Desarrollo, 2017).

Table 3 shows the average paper-to-patent ratio of the total population of full time academics, along with the academic inventors, for the ten years for which data could be gathered. There is a clear systematic difference between the ratios for the total population and the group of patenting academics. Above all, only a small fraction of the faculty members (0.20) patent at all. Twenty-two professors have patented between 2008 and 2017, seven of them have between two and six patents in total.

Table 3 Comparative paper to patent ratios, total population and patenting academics

\begin{tabular}{|c|c|c|c|c|c|c|c|c|c|c|}
\hline & 2008 & 2009 & 2010 & 2011 & 2012 & 2013 & 2014 & 2015 & 2016 & 2017 \\
\hline $\begin{array}{l}\text { Total population } \\
\text { (Full time academics that publish or patent) }\end{array}$ & 56 & 60 & 66 & 73 & 76 & 83 & 90 & 99 & 104 & 111 \\
\hline $\begin{array}{l}\text { Academic inventors } \\
\text { (Academics that patent) }\end{array}$ & 2 & 2 & 2 & 4 & 3 & 6 & 8 & 7 & 4 & 5 \\
\hline Academics publishing at least one paper & 44 & 48 & 56 & 55 & 65 & 65 & 72 & 85 & 92 & 95 \\
\hline $\begin{array}{l}\text { Paper-to-patent ratio } \\
\text { (Total population) }\end{array}$ & 65.0 & 72.0 & 45.0 & 29.8 & 76.3 & 32.7 & 31.6 & 31.3 & 96.0 & 53.7 \\
\hline $\begin{array}{l}\text { Paper-to-patent ratio } \\
\text { (Academic inventors) }\end{array}$ & 16.5 & 18.0 & 10.3 & 7.8 & 20 & 7.7 & 7.4 & 6.2 & 17.0 & 10.0 \\
\hline
\end{tabular}

Source: Records, Directorate of Transfer and Development, Pontificia Universidad Católica de Chile, December 2017 (Patents); and Records, Directorate of Innovation and Research, School of Engineering, Pontificia Universidad Católica de Chile, December 2017 (Publications).

Figure 3 presents the percentage of faculty members who published or patented every year between 2008 and 2017. In consistency with paper-to-patent ratios (Table 3), patenting shows up as a minor activity compared to academic publications. On average, only $5.1 \%$ of the faculty patent in any given year. Conversely, over $80 \%$ of the faculty publish as a minimum one paper in any given year. 
Figure 3 Percentage of faculty members publishing and patenting

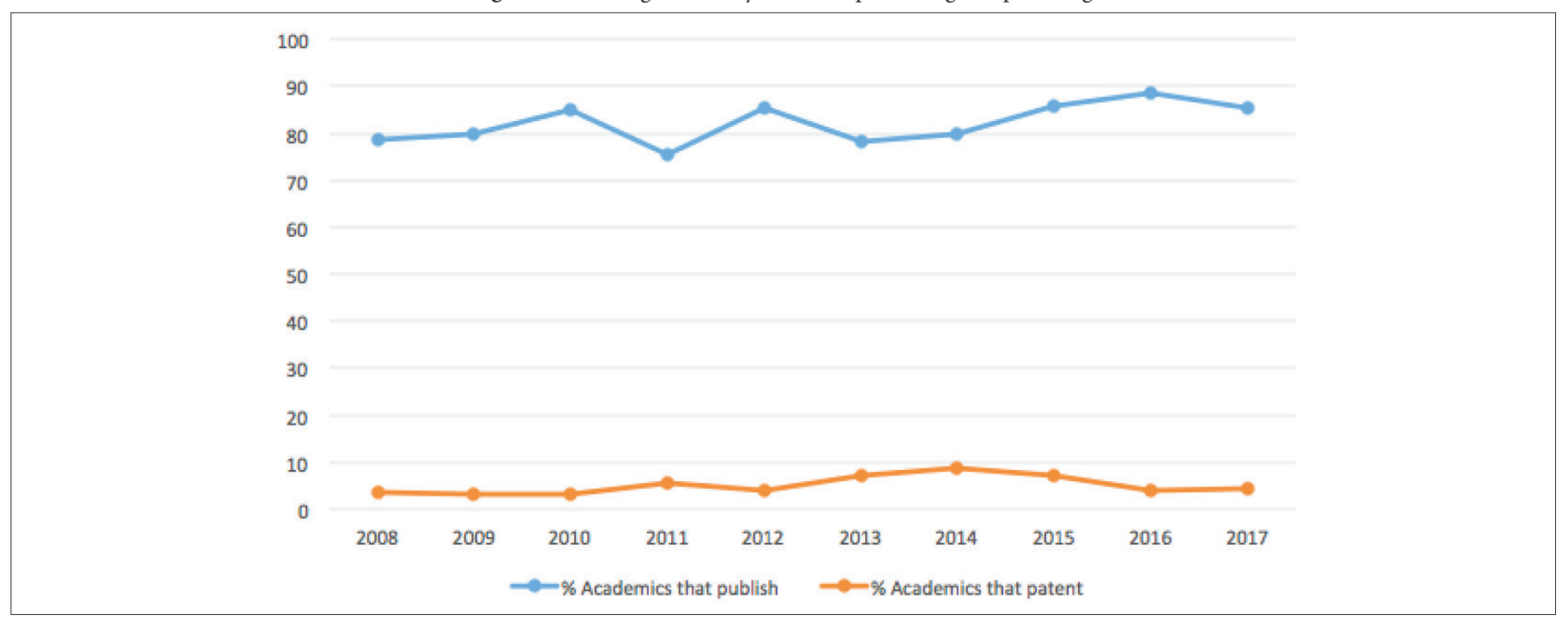

Source: Records, Directorate of Transfer and Development Pontificia Universidad Católica de Chile, December 2017 (Patents); and Records,

Directorate of Innovation and Research, School of Engineering, Pontificia Universidad Católica de Chile, December 2017 (Publications).

Figure 4 delves into this aspect by presenting the distribution of professors in terms of publishing (4a) and patenting (4b) frequency between 2008 and 2017. It is noteworthy the difference between both distributions. In coherence with Figure 3, the distribution of patenting faculty is highly skewed to the left. About $80 \%$ of the professors have never filed a patent application; only 6 faculty members have filed more than 2 applications with a maximum of 6 . Distribution of publishing faculty is also skewed to the left, although it has mass up to about 25 papers published, with three prolific authors producing over 40 papers in the period. $72 \%$ of the faculty members have published up to 20 papers, $14 \%$ more than 30 papers, while $9 \%$ have published 35 or more.

In a diagnostic report on academic entrepreneurship at UC Engineering, it was found that more than half of the professors are interested in undertaking academic entrepreneurial activities (Pontificia Universidad Católica de Chile, 2017). However, the main barrier, mentioned by the respondents to a survey, was lack of time to devote to this sort of activity, considering the framework for academic career assessment. Regarding potential proposals for actions to encourage academic entrepreneurship, the most important aspect, in the view of the respondents, was the possibility of having a comprehensive assistance process to support the development of academic entrepreneurial initiatives (Pontificia Universidad Católica de Chile, 2017). However, the idea that organizational support for knowledge transfer may significantly affect the performance of this activity has found limited support; despite similarity in the presence, staffing and capability of TTOs across universities, significant differences have been found in the scale and scope of knowledge transfer activities (HewittDundas, 2012). In any case, Hewitt-Dundas suggests that capability is less important in shaping knowledge transfer activity than the strategic priorities for knowledge transfer, arguing that even where capability is established, this will not directly generate activity if there is a 'disconnect' between the organizational supports and strategic priorities (Hewitt-Dundas, 2012).
Figure 4a Publication frequency

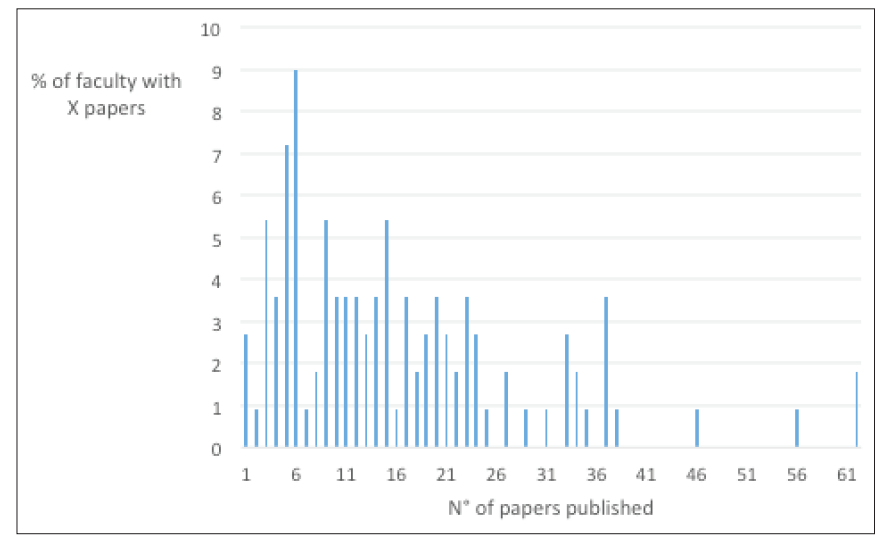

Figure $4 b$ Patent frequency

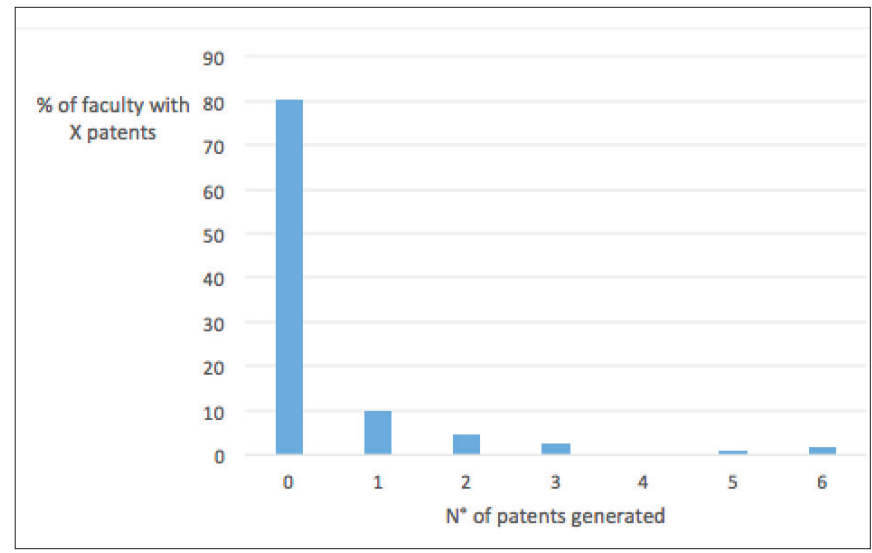

Source: Records, Directorate of Innovation and Research, School of Engineering, Pontificia Universidad Católica de Chile, December 2017 (Publications); Records, Directorate of Transfer and Development Pontificia Universidad Católica de Chile, December 2017 (Patents). 
Another piece of evidence, about the relevance of patenting in the transfer that reaches industry, is provided by the answers to the survey. The objective of the survey was to understand the UC Engineering's faculty members' perspective in respect of knowledge and technology transfer and its channels relative importance. Figure 5 shows the response to one of the questions, the relative importance credited to nine different channels of technology transfer. Respondents classified important or very important every channel, ranking collaborative research (22.9\%) as the most important knowledge and technology transfer channel to industry, followed closely by publications $(22.1 \%)$. Only informal channels (ex.: conversations) was ranked below patenting and licensing which reached $11.1 \%$.

Figure 5 Perception of relative importance of knowledge and technology transfer to industry

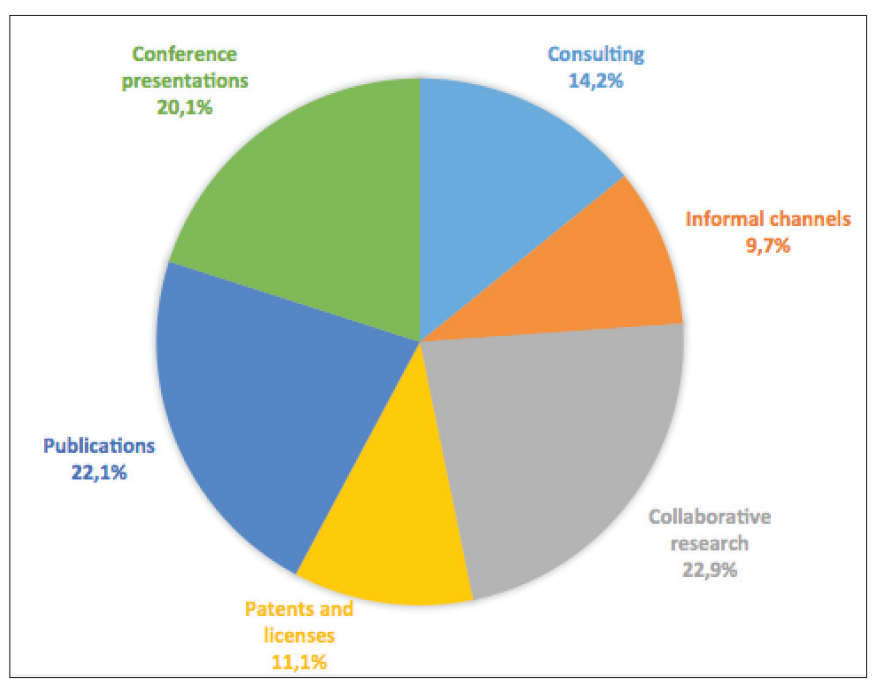

Source: Survey to UC Engineering faculty, January 2018.

Table 4 presents our survey results and compares them with Agrawal \& Henderson (2002). It is noticeable the relatively low importance that UC Engineering faculty members assign to patenting and licensing. It was deemed important or very important as a knowledge and technology transfer channel by $11.1 \%$ of the respondents. Both sets of results rank patents and licensing as relatively unimportant $(11.1 \%$ versus 9.0\%), while both sources view consulting, publishing and collaborative research accounting for $59.2 \%$ versus $76.3 \%$ as important or very important channels. All in all, these results show the relatively low importance that UC Engineering academics assign to patenting and licensing, and is consistent with the hypothesis formulated by Agrawal \& Henderson (2002) that patenting constituted a relatively small channel for the transfer of knowledge form university to industry. There are potential limitations associated with the fact that I asked about perceptions of relative importance of knowledge and technology transfer channels, which may be influenced by the channels that involve more interaction with firms that use individual academics' particular knowledge. Faculty might overestimate the relative importance of channels that involve more interaction with firms that use their particular knowledge, and to underestimate the importance of other channels. In addition, I considered only those faculty members that have published or patented at least once. It could be expected that this group overestimate, to some extent, the importance of publishing as over $80 \%$ have published as a minimum one paper in any given year; and underestimate patenting and licensing importance, as about $80 \%$ of the academics have never filled any patent application.

Table 4 distribution of perceived importance of channels of knowledge and technology transfer to industry

\begin{tabular}{l|c|c}
\hline & $\begin{array}{c}\text { What is your perception } \\
\text { of relative importan- } \\
\text { ce of the following } \\
\text { knowledge and techno- } \\
\text { logy transfer channels } \\
\text { (UC Engineering, } \\
\text { 2018): }\end{array}$ & $\begin{array}{c}\text { Estimate the portion } \\
\text { of the influence your } \\
\text { research has had on } \\
\text { industry activities, } \\
\text { including research, } \\
\text { development and } \\
\text { production that was } \\
\text { transmitted to each of } \\
\text { the following chan- } \\
\text { nels (MIT, 2000): }\end{array}$ \\
\hline Consulting & $\begin{array}{c}\text { \% Total that responded } \\
\text { at least "important" } \\
\text { (4 on 5-point Likert } \\
\text { scale) Normalized to } \\
\text { equal 100 }\end{array}$ & $\begin{array}{c}\text { Normalized to equal } \\
100\end{array}$ \\
\hline $\begin{array}{l}\text { Informal channels } \\
\text { (ex. conversations) }\end{array}$ & 14.2 & 34.4 \\
\hline Collaborative research & 9.7 & 8.6 \\
\hline Patents and licenses & 22.9 & 16.6 \\
\hline Publications & 11.1 & 9.0 \\
\hline Conference \\
presentations
\end{tabular}

Source: Agrawal \& Henderson. Putting Patents in Context: Exploring Knowledge Transfer from MIT. Management Science Vol. $48 \mathrm{~N}^{\circ} 1$, January 2002 (MIT, two engineering departments). Survey to UC Engineering faculty, January 2018 (UC Engineering).

As a whole, all these results are consistent with the idea that patenting and licensing represent a relatively small channel for the transfer of knowledge from academia to industry. It is remarkable, despite the anecdotal nature of the comparison, the extreme importance of publications over patents in terms of production, when comparing UC Engineering to MIT's engineering departments. Average publications per academic are more than $50 \%$ more frequent, and patenting per academic over four times less frequent, at UC Engineering, as shown in Table 2. In terms of academic perceptions of the relative importance of knowledge and technology transfer channels, however, patenting and publishing results are much closer in terms of order of magnitude as seen in Table 4. Although UC Engineering academics found relatively more important publication over patenting in a ratio of 2:1, versus 2.8:1 gathered by Agraval \& Henderson; in terms of average production of papers per patent per year, ratios are 48:1 versus 7:1 respectively (see Table 2). Furthermore, despite that UC Engineering academics deemed important or very important publications (22\%) over patenting (11\%), they publish almost 50 times more than patent.

It is not easy to speculate in respect of these differences about patenting versus publishing in terms of perceptions and production due to 
the complex and systemic nature of technology transfer activity. Causes could be found in the level of sophistication or "demand" of technology transfer from industry, trust of industry in domestic academia capability to deliver on time and budget, lack of match amongst disciplines or characteristics of the knowledge addressed, academic entrepreneurial culture, incentivation schemes for academics, lack of complementarities with other technology transfer channels, to name some. Alternatively, it might be simply that papers are preferred in the domestic industry context over patents as a channel to gain knowledge from academia. This is a matter that remains unclear.

Notwithstanding, despite the numerous pitfalls it has as a measure, focus on patenting appears to be likely to continue providing a useful lens to consider the impact of a university on the economy, even though patents represent a relatively small portion of total knowledge transferred. Reporting ratios of patents in a given year over three-year average and considering these ratios related to resource measures are suggested measures to increase robustness compared to plain patenting ratios per year.

\section{Relationship between patenting and publishing behavior}

I now look at the degree to which these two variables, patenting and publishing, are related. From a quantitative perspective at UC Engineering, Figure 6 shows the plot of total patents versus total publications per academic (6a). Similar to Agrawal \& Henderson, there is no clear relationship between the two variables, and the plot represent the strong minority of patenting activity compared to publications. A similar plot is then presented where data has been adjusted to the number of years each academic has been active (6b), paper and patent production has been divided by the number of years each professor has been working at UC Engineering during the period investigated. Again, no clear relationship is evident. If anything, the plot shows a few academics that publish heavily but does not patent, and that no academic inventor publish more than four papers per year. In any case, it is noteworthy that all academic inventors at UC Engineering publish, and in general, they publish a big deal more than the total population considered. The latter is a difference from Agrawal \& Henderson's research as they found a few academics patenting heavily but not publishing.

Figure 6a Papers versus patents output, $2008-2017(\mathrm{n}=111)$

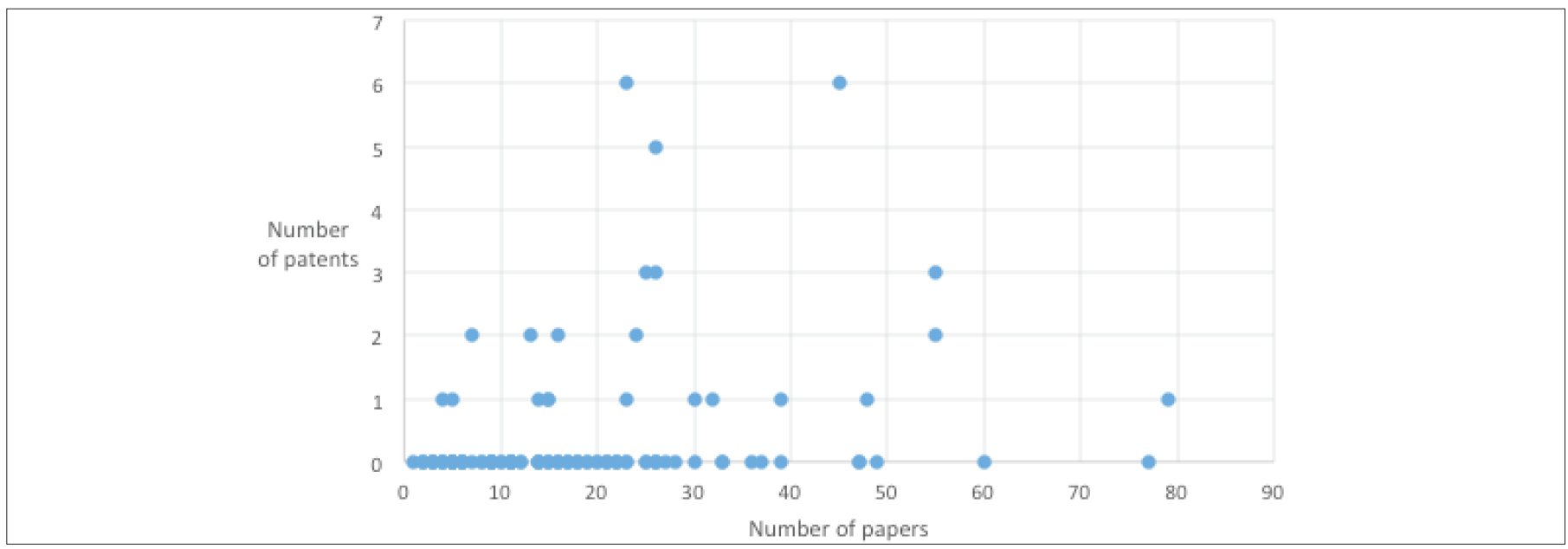

Figure 6b Papers versus patents output per year, 2008 - 2017 ( $\mathrm{n}=111)$

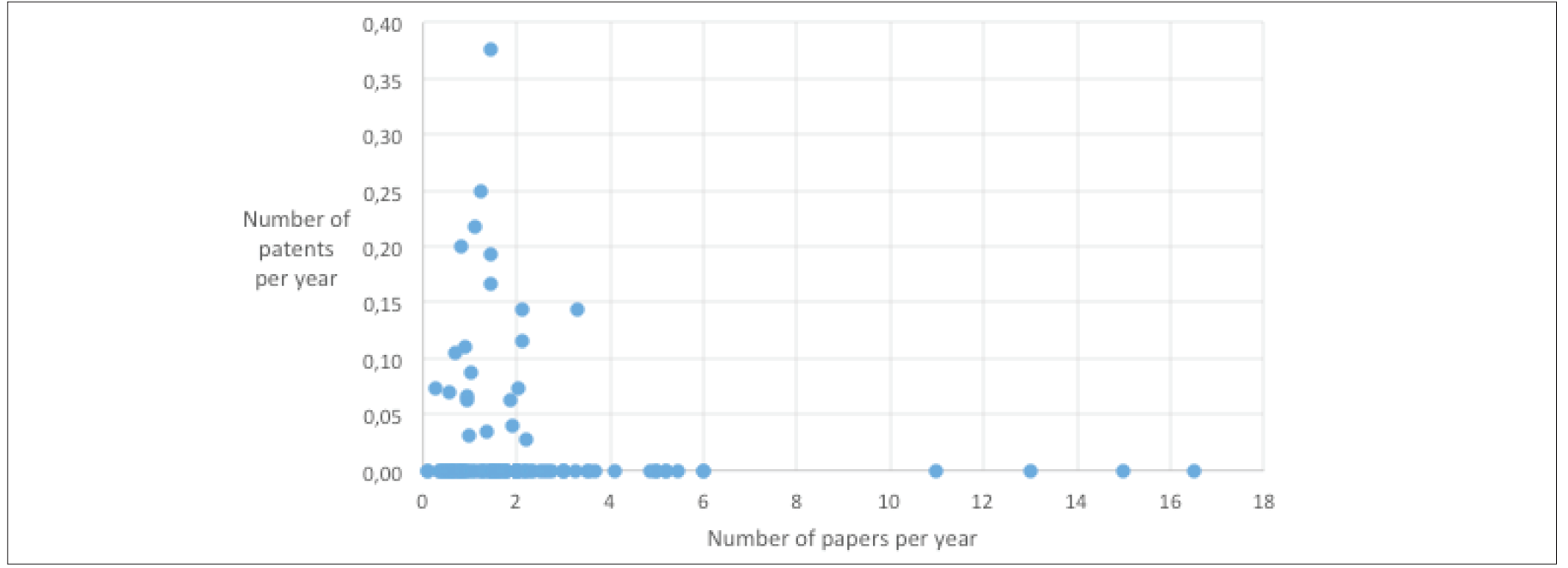

Source: Records, Directorate of Innovation and Research, School of Engineering, Pontificia Universidad Católica de Chile, December 2017 (Publications); Records, Directorate of Transfer and Development Pontificia Universidad Católica de Chile, December 2017 (Patents). 
Table 4a presents another step in this analysis looking at academic inventors, showing correlation coefficients for some flow measures of patenting and publishing behavior. Three one-year lag variables have been included to capture any difference arising from the fact that I am using publication and patent application dates. Thus, it is reasonable to assume that a paper and a patent written in the same year would have a difference as publication cycles may last more than one year. First, a low to moderate positive correlation was found across publishing behavior over time $(0.37,0.02$, and 0.60 are the correlation coefficients of Paper ${ }_{t}$ with Paper $(t-1)$, Paper $_{(t-2)}$, and Paper $\left.(t-3)\right)$. Though no clear correlations is evident in respect of patenting behavior over time $(-0.02,-0.26$, and 0.20 are the correlation coefficients of Patent with Patent ${ }_{(\mathrm{t}-1)}$, Patent $_{(\mathrm{t}-2)}$, and Patent $\left.\mathrm{t}_{(\mathrm{-}-3)}\right)$. Similarly, there is no evidence that patenting and publishing behavior are correlated with each other $(-0.19,0.44,-0.1291$ and 0.2531 are the correlation coefficients of Paper ${ }_{t}$ with Patent $_{t}$, Patent $_{(\mathrm{t}-1)}$, Patent ${ }_{(\mathrm{t}-2)}$, and Patent ${ }_{(\mathrm{t}-3)}$ respectively).

Table 4a Correlation matrix: patenting and publishing

\begin{tabular}{|c|c|c|c|c|c|c|c|c|}
\hline & Paper $_{t}$ & Paper $_{t-1}$ & Paper $_{t-2}$ & Paper $_{t-3}$ & Patent $_{t}$ & Patent $_{t-1}$ & Patent $t_{t-2}$ & Patent $_{t-3}$ \\
\hline Paper $_{t-1}$ & 0.3745 & 1 & & & & & & \\
\hline Paper $_{t-3}$ & 0.6026 & 0.4433 & 0.2990 & 1 & & & & \\
\hline Patent $_{t}$ & -0.1948 & -0.1785 & -0.2126 & -0.4609 & 1 & & & \\
\hline Patent ${ }_{t-3}$ & 0.2531 & -0.0168 & 0.0679 & -0.0314 & 0.1979 & -0.0690 & -0.3499 & 1 \\
\hline
\end{tabular}

In short, on the one hand a low to moderate positive correlation was found across publishing over time; on the other, the number of papers written three years ago is not related to the patent applications filed today, or in any of the last three years. The central finding re- mains, patenting and publishing activity does not appear to be significantly related. This is a difference with Agrawal \& Henderson, as they found a clear correlation across publishing and across patenting behavior, but little evidence of patenting and publishing correlation.

Table $4 \mathbf{b}$ Correlation matrix: patenting and publishing (Stock measures)

\begin{tabular}{l|c|c|c|c|c}
\hline & Total papers & Total patents & Total years & Papers per year & Patents per year \\
\hline Total papers & 1 & & & & \\
\hline Total patents & 0.1578 & 1 & & & \\
\hline Total years & 0.5318 & 0.3395 & 1 & & \\
\hline Papers per year & 0.6044 & -0.1102 & -0.2162 & 1 & 1 \\
\hline Patents per year & -0.2254 & 0.6413 & -0.3619 & 0.0724 & \\
\hline
\end{tabular}

In a similar manner, Table $4 \mathrm{~b}$ presents correlation coefficients for stock measures of patenting and publishing behavior for academic inventors, including totals and averages. Although a measure of correlation is present $(0.16)$ between total papers and total patents, this is largely caused by the variance in the numbers of years that the academics have been working at the university. When this factor is controlled for by taking paper and patent output averaged, the coefficient is much smaller (0.07). Again, no correlation is apparent between publishing and patenting behavior.

\section{Patens and papers: substitute or complement?}

Now, I pay attention to the extent to which patents are complementary or substitute for publications in the university context. As argued in Section 2, some authors suggest a complementary effect whilst others have found evidence of a crowding out effect. So far, our evidence suggest no significant relation amongst them. In this respect, as shown in Figure 7, when UC Engineering academics were asked to what extent knowledge in their individual technological field is pri- marily expressed in 'scientific documents' (e.g. journal articles, conference papers, and proceedings) or in 'grey literature' (e.g. patents, industrial reports, confidential memorandums, discussion lists), they chose clearly 'scientific documents' over 'grey literature. Thus, in the academics' perspective, knowledge in their respective technological field is mainly expressed in scientific documents instead of grey literature. This is consistent with our data that shows the strong prevalence of publishing over patenting.

If patenting activity is a substitute for publishing, it would be expectable publication rates negatively correlated to patent figures. However, correlation coefficients are non significant and even they alternate sign over time (Tables $4 \mathrm{a}$ and $4 \mathrm{~b}$ ). Thus, our results suggest that no substitution effect is evident among patenting and publishing activity. By the same token, based on our correlation results complementarity amongst patenting and publishing could be neglected as well. In addition, when publication means of total population and academic inventors are divided by the respective average number of years at UC Engineering (see Table 1), the ratios of publications per year (1.40 and 
1.36 respectively) are rather similar. This suggest that seniority would not be an influential factor in terms of average publication production. Conversely, when patenting means are controlled in the same manner (0.03 and 0.09 respectively), the difference is substantial, suggesting that seniority could be an influential factor on patenting behavior.

Figure 7 Primary expression of UC Engineering's academics knowledge

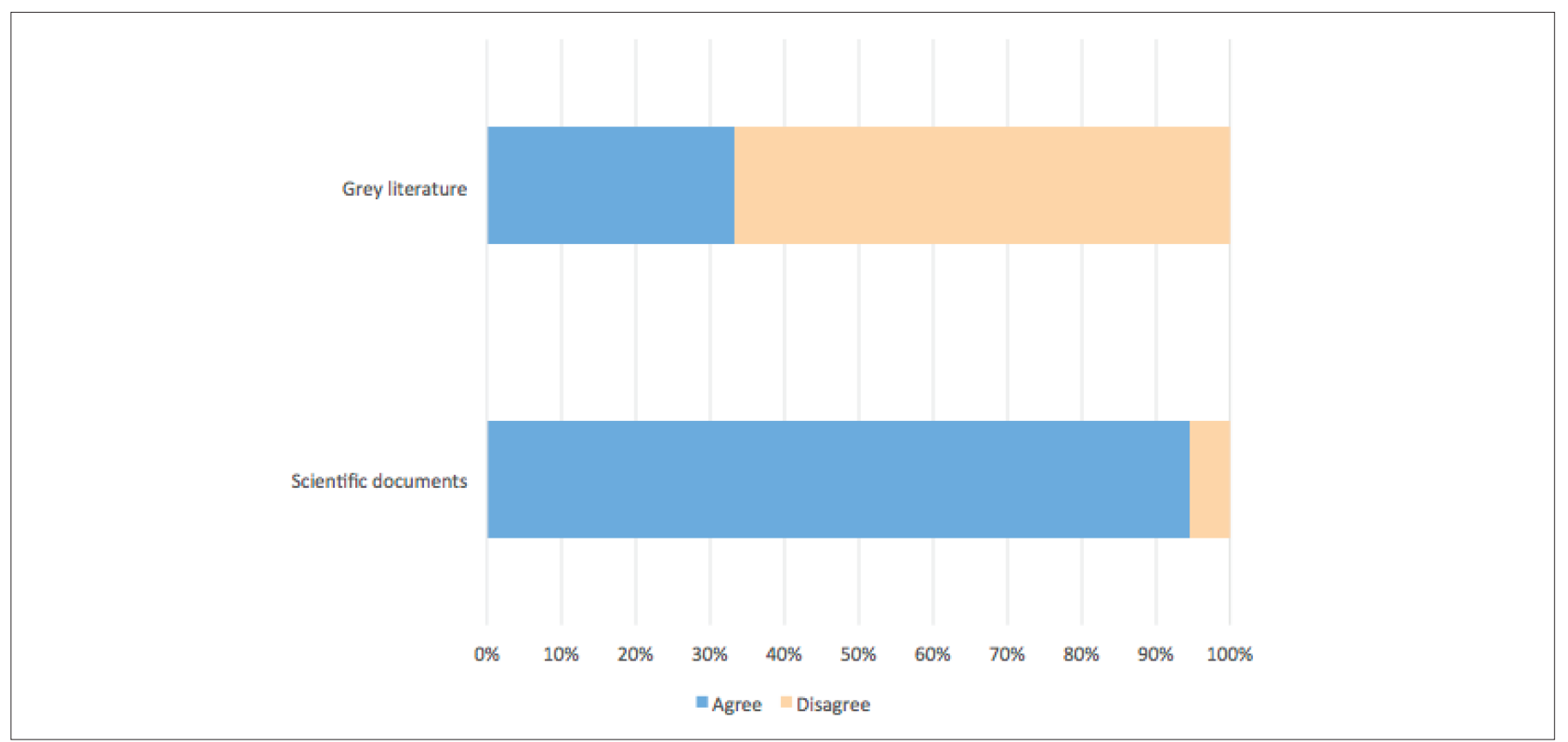

Source: Survey to UC Engineering faculty, January 2018.

\section{Conclusion}

What are the findings of this exploratory research? I began this paper by asking to what extent patents are representative of the magnitude and impact of the knowledge transferred from university to industry. This question is highly relevant for policy-makers who attempt to encourage the diffusion of university-generated technologies within the wider economy. Our analysis of UC Engineering has shown some conclusions.

The steady increase in the number of academics at UC Engineering since 2008 until 2017 (56 to 111), has been accompanied by growth in annual publishing (130 to 376 ) and patenting (2 to 7) outputs at UC Engineering. Patenting is an activity undertaken by a small portion of the faculty members (about $5 \%$ in any given year), resulting in a relatively small channel for the transfer of knowledge and technology to industry, in consistency with the widely accepted idea in this respect. Moreover, $80 \%$ of the faculty members have never filed a patent application. Despite that UC Engineering faculty members deem publications (22\%) more important than patenting (11\%) as a channel to transfer technology to industry, I found that they publish, in average, almost 50 times more than patent.

An anecdotal comparison of UC Engineering and two engineering departments at the MIT (Agrawal \& Henderson, 2002) suggests a much higher relative importance in terms of production counting, for the former, of publication over patenting activity as a technology trans- fer channel (48:1 versus 7:1 are the respective average publication to patent rates per academic per year). In average, UC Engineering academics publish more (3:2) but patent a big deal less (1:4) compared to the MIT sample. Neither complementary nor substitution effect was found amongst publishing and patenting. For UC Engineering, only a low to moderate positive correlation was found across publishing behavior over time, but not across patenting. Seniority was not found to be related with publishing behavior, but academic inventors compared to the total group of academics tend to have much longer tenures (20.6 versus 13.4 years in average). The UC is the Chilean university with the higher number of patent applications in country. In this respect, in the US, the MIT is one highly prolific university. However, although in terms of relative importance of publishing over patenting, as a technology transfer channel, UC Engineering and the sample from the MIT are relatively similar in the perception of faculty (2:1 versus 2.8:1); in terms of production counting, the ratios showed a substantial difference. This is the biggest dissimilarity that I found in our comparison. I can only speculate about this situation, suggesting that at the level of knowledge transfer activity portrayed, differences about publishing versus patenting might be related to the complex and systemic nature of technology transfer activity. Also, in the sort of "demand" of technology transfer from industry, weak trust of industry in domestic academia's capability to deliver on time and budget, divergence amongst the characteristics of the knowledge addressed, publication-oriented academic culture, not completely aligned incentivation schemes for academics, lack of complementarities with other technology transfer channels, to name some. 
In respect to the exploration about the degree to which patents are representative of the magnitude of the knowledge transferred from university to industry, I found that in UC Engineering, in general, during the last 10 years patenting and publishing activity have been increasing steadily. However, patenting is perceived by academics as a relatively less important technology transfer channel compared to publishing (2:1), and in terms of production counting it appears even less relevant (almost 50:1). It is important to stress that constraints on the data available currently limits our ability to explore this specific type of technology transfer activity in a more granular manner or expand our analysis to consider other technology transfer channels. Notwithstanding, the anecdotal comparison with the MIT lead us to ask if there are some obstacles or barriers impeding a more robust patenting activity; or even hampering other technology transfer channels. Taking into account the magnitude of the differences found, it appears of the utmost importance to detect and overcome obstacles and barriers considering increasing pressures from elements as diverse as societal expectations, fast technological change, firms' innovation needs and market pressures inter alia.

In the broader knowledge and technology transfer context, availability of financial resources to undertake research and organizational attention to academics productivity balancing publishing and patenting activity, appear as essential inputs. The former from public or private sources, and the latter by means of academic entrepreneurial culture and academic career promotion rules. Another key element is alignment to the strategic objective of helping domestic economy to find its future and sustainable competitive advantage. Provided that these fundamentals are in place, a more straightforward transfer of academic knowledge into the industrial domain could be expected. Clearly, there is much to do to advance knowledge. On the one hand, a finer analyses of academic activity. Closer attention to faculty behavior, in respect of multiple technology transfer channels, across departments over time should be enlightening. Building and maintaining robust databases could assist more effective management of academic activity and interaction with industry. On the other, the addition of the industrial counterpart perspective would enable a more comprehensive perspective.

\section{Acknowledgements}

This research was partly funded by CONICYT, the Chilean agency tasked to underpin Chile's scientific and technological development, through the project I7817010004 "Strengthening the Industry - University relationship and the technology transfer capability of the DICTUC SA - UC Engineering system". The author would like to thank professors Julio Pertuzé and Juan Carlos Salas from the UC Engineering School for insightful comments and valuable suggestions, and to Erika Rosales and Alexi Del Canto for their support and access to data.

\section{About author}

Hector Gaete works as a researcher in DICTUC SA a company affiliated to the Pontificia Universidad Católica de Chile, in Santiago, Chile. He holds an MSc and a PhD in Acquisition Management from Cranfield University in the United Kingdom. He is focused on stren- gthening capabilities aimed to deploy a more effective Industry - University relationship, enhancing technology transfer activity in which DICTUC participates.

\section{References}

Arvanitis, Spyros; Kubli, Ursulina; Woerter, Martin. 2008. University-Industry Knowledge and Technology Transfer in Switzerland: What University Scientists Think About Co-operation with Private Enterprises. Research Policy No37 (2008). Elsevier B.V. https://doi. org/10.1016/j.respol.2008.07.005

Bekkers, Rudi; Bodas Freitas; Isabel Maria. 2008. Analysing Knowledge Transfer Channels Between Universities and Industry: To What Degree do Sectors Also Matter? Research Policy N³7 (2008). Elsevier B.V. https://doi.org/10.1016/j.respol.2008.07.007

Bodas Freitas, Isabel Maria; Marques, Rosane Argou Marques; De Paula e Silva, Evando Mirra. 2013. University - Industry Collaboration and Innovation in Emergent and Mature Industries in new Industrialized Countries. Research Policy N42 (2013). B.V. Elsevier. https://doi.org/10.1016/j.respol.2012.06.006

Bozeman, Barry; Rimes, Heather; Youtie, Jan. 2015. The Evolving State-of-the-art in Technology Transfer Research: Revisiting the Contingent Effectiveness Model. Research Policy N 44 (2015). https://doi. org/10.1016/j.respol.2014.06.008

Bruneel, Johan; D’Este, Pablo; Salter, Ammon. 2010. Investigating the Factors that Diminish the Barriers to University - Industry Collaboration. Research Policy N³9 (2010). Elsevier B.V. https://doi. org/10.1016/j.respol.2010.03.006

Clarysse, Bart; Tartari, Valentina; Salter, Ammon. 2011. The Impact of Entrepreneurial Capacity, Experience and Organizational Support on Academic Entrepreneurship. Research Policy N40. Elsevier B. V. https://doi.org/10.1016/j.respol.2011.05.010

CONICYT. 2017. Dimensiones de la Producción Científica Nacional - Programa de Información Científica CONICYT. URL: https://dataciencia.conicyt.cl/interfaz/. Downloaded on November 20th 2017. Consejo Nacional de Innovación para el Desarrollo. 2017. Estrategia Nacional de Innovación para el Desarrollo 2nd. Ed.

Crespi, Gustavo; D'Este, Pablo; Fontana, Roberto; Geuna, Aldo. 2011. The Impact of Academic Patenting on University Research and its Transfer. Research Policy $\mathrm{N}^{\circ} 40$ (2011). Elsevier B.V. https://doi. org/10.1016/j.respol.2010.09.010

DICTUC SA. 2016. Annual Report 2015. https://www.dictuc.cl/wpcontent/uploads/2018/01/Annual-Report-Dictuc-2016-.pdf

Giuliani, Elisa; Morrison, Andrea; Pietrobelli, Carlo; Rabellotti, Roberta. 2010. Who are the Researchers that are Collaborating with Industry? An Analysis of the Wine Sectors in Chile, South Africa and Italy. Research Policy N³9 (2010). https://doi.org/10.1016/j.respol.2010.03.007 
Hewitt-Dundas, Nola. 2012. Research Intensity and Knowledge Transfer Activity in UK Universities. Research Policy N 41 (2012). Elsevier B.V. https://doi.org/10.1016/j.respol.2011.10.010

Johnson, William. 2011. Managing University Technology Development Using Organizational Control Theory. Research Policy $\mathrm{N}^{\circ} 40$ (2011). Elsevier B.V. https://doi.org/10.1016/j.respol.2011.10.010

Kleinknecht, Alfred \& Reinders, Henk Jan. (2012). How Good Are Patents as Innovation Indicators? Evidence from German CIS Data. Innovation and Growth: From R\&D Strategies of Innovating Firms to Economy-wide Technological Change. Oxford University Press. DOI: 10.1093/acprof:oso/9780199646685.003.0006

Landry, Rejean; Saihi, Malek; Amara, Nabil; Ouimet, Mathieu. 2010. Evidence on How Academics Manage their Portfolio of Knowledge Transfer Activities. Research Policy N³9 (2010). Elsevier B.V. https:// doi.org/10.1016/j.respol.2010.08.003

Maietta, Ornella Wanda. 2015. Determinants of University - Firm R\&D Collaboration and its Impact on Innovation: A Perspective from a low-tech Industry. Research Policy N 44 (2015). B.V. Elsevier. https://doi.org/10.1016/j.respol.2015.03.006

National Academy of Inventors. 2017. Top 100 Worldwide Universities Granted U.S. Utility Patents in 2016. http://www.academyofinventors.com/pdf/top-100-universities-2016.pdf

Perkmann, Markus, Kin, Zella \& Pavelin, Stephen. 2011. Engaging Excellence? Effects of Faculty Quality on University Engagement with Industry. Research Policy $\mathrm{N}^{\circ} 40$ (2011). Elsevier B.V. https://doi. org/10.1016/j.respol.2011.01.007
Perkmann, Markus; Tartari, Valentina; McKelvey, Maureen; Autio, Erikko; Broström, Anders; D’Este, Pablo; Fini, Riccardo; Geuna, Aldo; Grimaldi, Rosa; Hughes, Alan; Krabel, Stefan; Kitson, Michael; Llerena, Patrick; Lissoni, Franceso; Salter, Ammon; Sobrero, Maurizio. 2013. Academic Engagement and Commercialisation: A Review of the Literature on University - Industry Relations. Research Policy N42 (2013). Elsevier B.V. https://doi.org/10.1016/j.respol.2012.09.007

Petralia, Sergio; Balland, Pierre-Alexandre; Morrison, Andrea. 2017. Climbing the Ladder of Technological Development. Research Policy No46 (2017). Elsevier B.V. https://doi.org/10.1016/j.respol.2017.03.012

Pontificia Universidad Católica de Chile. 2016. School of Engineering. RESEARCH@ENGINEERING.UC.CL.

Pontificia Universidad Católica de Chile. 2017. School of Engineering. Report Diagnostic of Academic Entrepreneurship Situation.

Rasmussen, Einar; Borch, Odd Jarl. 2010. University Capabilities in Facilitating Entrepreneurship: A Longitudinal Study of Spin-off Ventures at Mid-range Universities. Research Policy No39 (2010). Elsevier B.V. https://doi.org/10.1016/j.respol.2010.02.002

Sengupta, Abhijit \& Ray, Amit S. 2017. University Research and Knowledge Transfer: A Dynamic View of Ambidexteriry in British Universities. Research Policy N46 (2017). https://doi.org/10.1016/j.respol.2017.03.008

Van Looy, Bart; Landoni, Paolo; Callaert, Julie; Van Pottelsberghe; Sapsalis, Eleftherios; Debackere, Koenraad. 2011. Entrepreneurial Effectiveness on European Universities: An Empirical Assessment of antecedents and Trade-Offs. Research Policy $N^{\circ} 40$ (2011). Elsevier B.V. https://doi.org/10.1016/j.respol.2011.02.001

World Intellectual Property Organization. 2017. World Intellectual Property Indicators 2017. http://www.wipo.int/edocs/pubdocs/en/ wipo_pub_941_2017.pdf 
